\title{
Análise multitemporal dos focos de calor na Reserva Biológica do Gurupi-MA
}

\author{
Paula Fernanda Pinheiro Ribeiro Paiva ${ }^{1}$, Orleno Marques da Silva Junior ${ }^{1}$, Maria de Nazaré Martins Maciel ${ }^{1}$, \\ Thais Gleice Martins Braga ${ }^{1}$, Eduardo Saraiva da Rocha ${ }^{1 *}$, Luana Helena Oliveira Monteiro Gama ${ }^{1}$
}

\begin{abstract}
RESUMO: A Unidade de Conservação REBIO do Gurupi é um dos últimos remanescentes de Floresta Amazônica no Estado do Maranhão. O uso do geoprocessamento e sensoriamento remoto é fundamental na detecção de focos de calor e queimadas. Com o objetivo de analisar a densidade de focos de calor na REBIO do Gurupi, através de técnicas de geoprocessamento e sensoriamento remoto nos anos de 1998, 2006 e 2016. Construiu-se um banco de dados em ambiente SIG ArcGis 10.1, utilizando a metodología do estimador de densidade Kernel. Foram detectados 1.414 focos de calor pelos satélites NOAA, ERS-2, AQUA, TERRA, GOES, ATSR. O ano de maior incidência foi o de 2006 na proximidade do município de Centro Novo do Maranhão representado 57,6 \% de focos detectados. Fazendo o comparativo entre os anos houve uma tendência de crescimento nos meses de setembro e dezembro de 1998 e significativa diminuição de focos de calor detectados nos meses de outubro, novembro e dezembro de 2016.
\end{abstract}

Palavras-chave: Desmatamento, Unidade de Conservação, Maranhão.

\section{Multitemporal analysis of heat sources in the Gurupi-MA Biological Reserve}

ABSTRACT: The REBIO Conservation Unit of Gurupi is one of the last remnants of the Amazon Forest in the State of Maranhão. The use of geoprocessing and remote sensing is fundamental in the detection of heat sources and fires. With the objective of analyzing the density of heat sources in the REBIO of Gurupi, through geoprocessing and remote sensing techniques in the years of 1998, 2006 and 2016. A database was built in ArcGis 10.1 GIS environment, using the methodology of the kernel density estimator. 1,414 foci of heat were detected by the satellites NOAA, ERS-2, AQUA, TERRA, GOES, ATSR. The year of greatest incidence was 2006 in the proximity of the municipality of Centro Novo do Maranhão, representing 57.6\% of detected foci. Comparing the years, there was a trend of growth in the months of September and December of 1998 and a significant decrease in the foci of heat detected in the months of October, November and December of 2016.

Keywords: Deforestation, Conservation Unit, Maranhão.

\section{INTRODUÇÃO}

O meio ambiente e sua evolução natural estão sujeitos às constastes mudanças provocadas por ações antrópicas.

A floresta amazônica ocupa mais de 3,2 milhões de quilômetros quadrados, salvaguardando quase um terço das florestas tropicais do mundo, um quinto das águas doces superficiais, ao qual exerce papel fundamental para a regulação do clima regional e global (UHL et al., 1997; VERÍSSIMO, 2012).

A Reserva Biológica (REBIO) do Gurupi que faz parte do bioma Amazônia, abriga a floresta ombrófila densa montana, no Planalto Setentrional Pará-Maranhão, recortado pelas Serras da Desordem e do Tiracambu. Dentre as espécies ameaçadas protegidas nesta UC, estão: o gato-do-mato (Leopardus tigrinus), onça-pintada (Panthera onca), araçari-de-pescoço-vermelho (Pteroglossus bitorquatus bitorquatus) e triba-pérola (Pyrrhura lepida lepida). A composição florística representa grande diversidade, com muitas espécies de valor comercial, como maçaranduba (Manilkara huberi), ipê (Tabebuia sp.), jatobá (Hymenea coubaril), amarelão (Euxylophora paraensis), sapucaia (Lecythis pisonis), e o cedro (Cedrela odorata). A abundância dessas espécies tem diminuído consideravelmente, devido a ocorrência de altos índices de desmatamento (MOURA, 2011; IBAMA 1999; PINHEIRO 2019; INPE 2019).

Com uma grande riqueza de madeiras nobres, essa Reserva assume um importante papel para a manutenção da biodiversidade da flora local e nacional, o que a torna um grande atrativo para a indústria madeireira, já que é uma das últimas fontes de madeira da região (PINHEIRO et al., 2013).

Mesmo com a preocupação referente à preservação ambiental e, a degradação florestal, principalmente em função do desmatamento, assim também como da falta de prática de manejo 
sustentável das áreas, das queimadas decorrentes e da fragmentação do ecossistema, ocasionando a perda de biodiversidade, redução da ciclagem da água e reciclagem de nutrientes e redução da qualidade de vida, são impactos recorrentes nesta importante UC (ARAÚJO et al., 2012). As queimadas são uma ameaça que tem despertado atenção dos órgãos ligados ao meio ambiente, bem como da imprensa, com constantes informações sobre novos focos e seus prejuízos à saúde e ao ambiente.

A situação da Reserva Biológica do Gurupi é bastante crítica sob o ponto de vista da conservação. Segundo estimativas, resultantes do levantamento feito na região pelo Instituto Chico Mendes de Conservação da Biodiversidade, cerca de 70 a $80 \%$ da área já foi alterada pela extração da madeira. A REBIO enfrenta problemas relacionados à ocupação ilegal do território e ações criminosas associadas à extração ilegal da madeira. Quase 60 metros cúbicos de madeira extraída ilegalmente foram apreendidos por fiscais durante operação realizada no Sudoeste do Maranhão onde ao todo foram apreendidas 91 toras e 75 sacos de carvão. (ICMBio, 2017).

De uma maneira geral, a região do Gurupi é a única que ainda pode conservar populações viáveis da grande maioria das espécies de mamíferos de maior porte na porção amazônica do estado. Quanto às aves, a degradação da Amazônia maranhense poderá representar a perda de 122 espécies, ou cerca de $20 \%$ do total registrado (OREN; ROMA, 2011).

Atualmente, através de técnicas geoprocessamento e o sensoriamento remoto é possível fazer análise e manipulação de dados geográficos, ao qual são utilizados para detectar ações de desmatamento e índices de focos de calor em áreas de preservação ambiental, contribuindo assim para o monitoramento e controle dessas áreas, originando informações que são de fundamental importância para tomada de decisões para conservação do meio ambiente (TEIXEIRA, 2003).

O objetivo deste trabalho foi fazer uma análise quantitativa e temporal de focos de calor nas Unidades de Conservação REBIO do Gurupi fazendo comparativo entre os anos de 1998, 2006 e 2016. Utilizando técnicas e produtos de sensoriamento remoto e geoprocessamento, e realizar análise espacial de focos de calor e classificação de densidade verificando a ocorrência de queimadas na área em estudo.

\section{MATERIAL E MÉTODOS}

A área de estudo compreende a Reserva Biológica do Gurupi, Unidade de Conservação (UC) Federal, cuja gestão é realizada pelo Instituto Chico Mendes de Conservação da Biodiversidade (ICMBio), criada em 12 de janeiro de 1988 pelo Dec. $\mathrm{n}^{\circ}$ 95.614. Possui área de 271.197,51 hectares, e está localizada no noroeste do Maranhão (IBAMA, 2017), compreendendo partes do Município de Centro Novo do Maranhão, Bom Jardim e São João do Caru (Figura 1) o clima predominante é o tropical quente e úmido (As).

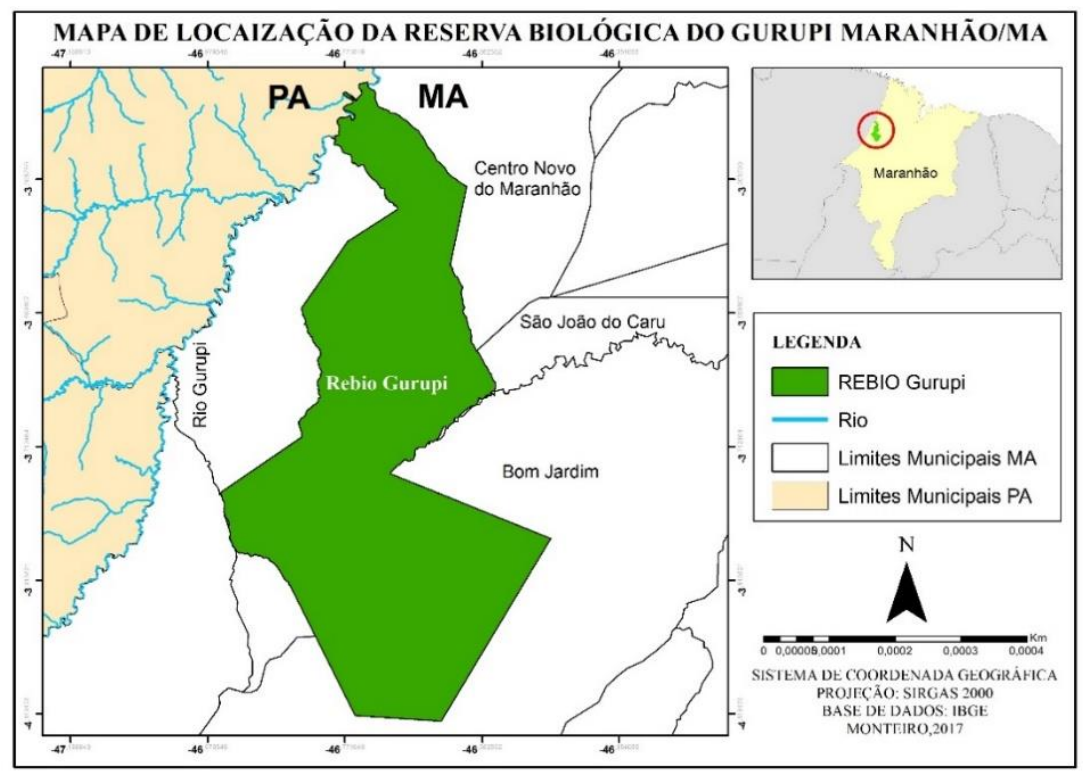

Figura 1: Mapa de localização da área de estudo. Fonte: Elaboração própria.

É a única unidade de conservação desta categoria em área amazônica a leste do Rio Xingu, tendo fundamental importância na conservação ambiental do estado do Maranhão, por estar entre os domínios da Amazônia, Cerrado e Caatinga. Contudo apresenta alto grau de desmatamento e fragmentação 
florestal, e um dos menores índices de desenvolvimento humano (MARTINS e OLIVEIRA, 2012). O Rio Gurupi, limite oeste da UC, é também o limite entre os Estados do Maranhão e do Pará. O relevo compreende as unidades geomorfológicas identificadas como planícies, depressões, tabuleiros, chapadas, patamares, planaltos e serras. Apresentam solos do tipo Latossolo amarelo, Plintossolo Pétrico e solos aluviais (MMA, 2016).

Os focos de calor foram detectados com base de dados de queimadas, coletados pelo satélite NOAA $(12,14,17,18,19)$, ERS-2, AQUA, TERRA, GOES $(12,13)$, ATSR, fornecido com diferentes sensores, para os anos de 1998, 2006 e 2016, disponíveis no site do Instituto Nacional de Pesquisas Espaciais (INPE).

Foi gerado um banco de dados em ambiente de Sistema de Informações Geográficas SIG ArcGis 10.1, inserindo-se arquivos em shapefile correspondentes aos limites territoriais das áreas protegidas, modelado o padrão de distribuição do conjunto de pontos, utilizando-se o estimador de densidade Kernel, que é uma metodologia para estimação de densidades no qual cada análise é calculada pela distância em relação a um valor central. Estes dados constituem-se de pontos que possuem informações básicas sobre os focos de calor.

Este tipo de operação é feito pelo ajuste de uma função bidimensional aos eventos considerados, em que a mesma realiza uma contagem de todos os pontos dentro de uma área de influência, estes são ponderados pela distância de cada um até o ponto que está sendo estimado (DRUCK et al., 2004). Tal processo possibilita uma visão qualitativa dos focos de calor na região de interesse.

A partir da densidade de kernel, foi criado um mapa de focos de calor classificado com níveis de densidades que variam de acordo com a cor e tonalidade sendo representados: Vermelho-escuro significa densidade muito alta; vermelho indica densidade alta; laranja escuro com densidade moderada; laranja densidade baixa, amarelo densidade muito baixa e branco sem registro de ocorrência.

\section{RESULTADOS E DISCUSSÕES}

Os focos de calor na REBIO do Gurupi foram mapeados tendo como base os anos de 1998, 2006 e 2016. De acordo com a análise dos dados, foram detectados 1.414 focos pelos satélites dentro dos limites da reserva. Os mapas de distribuição de focos de calor (Figura 2) mostram a situação espacial destes focos na área em estudo, e a partir de então pode-se analisar a ocorrência dos eventos de fogo em determinada região.

Estima-se que ocorreu eventos de fogo em unidades de conservação em torno de $15 \%$ de incidências de focos de calor, representando 52.522 hectares em 2005 e 19.645 ha em 2010 (SILVA et al., 2018).
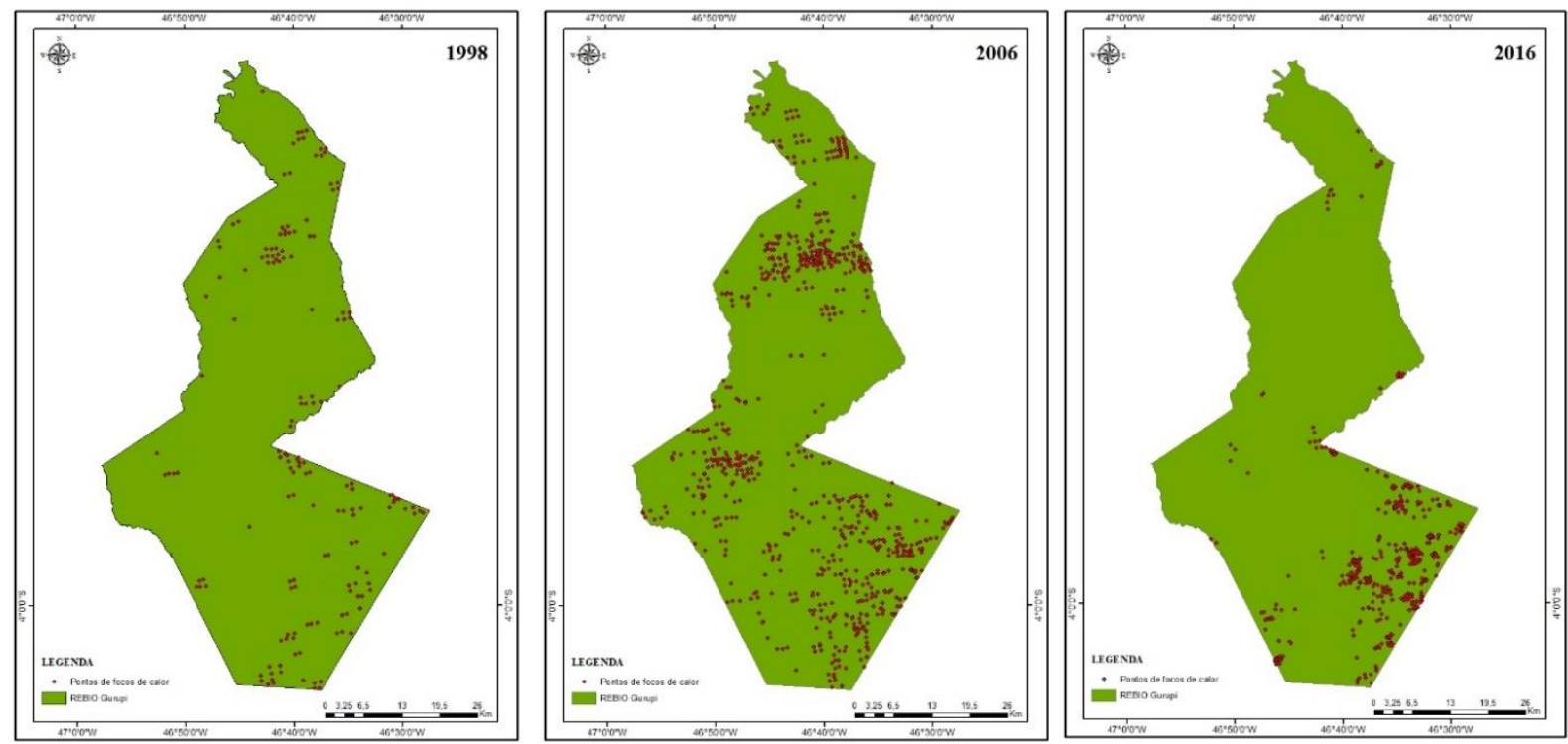

Figura 2: Mapas de distribuição de focos de calor. Fonte: Elaboração própria. 
Tabela 1- Focos de calor detectados nos anos de 1998, 2006 e 2016.

\begin{tabular}{cccc}
\hline MÊSSANO & $\mathbf{1 9 9 8 8}$ & $\mathbf{2 0 0 6 6}$ & $\mathbf{2 0 1 6 6}$ \\
\hline Janeiro & 0 & 0 & 0 \\
Fevereiro & 0 & 6 & 8 \\
Março & 0 & 0 & 0 \\
Abril & 0 & 0 & 0 \\
Maio & 0 & 0 & 0 \\
Junho & 0 & 0 & 4 \\
Julho & 0 & 0 & 1 \\
Agosto & 0 & 1 & 28 \\
Setembro & 5 & 3 & 36 \\
Outubro & 85 & 118 & 221 \\
Novembro & 43 & 279 & 169 \\
Dezembro & 28 & 379 & $\mathbf{4 6 7}$ \\
\hline Total & $\mathbf{1 6 1}$ & $\mathbf{7 8 6}$ & \\
\hline
\end{tabular}

Fonte: Elaboração própria.

$\mathrm{O}$ ano de maior incidência de focos de calor foi o de 2006, com cerca de 786 focos detectados, aumento bastante considerável em relação ao ano de 1998, que foram de 161 focos. O total registrado em 2006 pode estar relacionado aos fenômenos meteorológicos ocorridos entre junho e dezembro, em que foram registrados períodos extensos de estiagem. Já em 2016 houve redução no quantitativo de focos quando comparado ao ano de 2006, foram detectados 467 focos de calor.

Devido a sólida relação entre desmatamento e os incêndios ocasionados por ações antrópicas nos últimos anos, as ocorrências de incêndios florestais na Amazônia oscilou de um ano para o outro, provavelmente provocado por fatores abióticos constituintes (TASKER, ARIMA, 2016).

Foi elaborada uma tabela com os números de focos de calor e respectivos anos (Tabela 1) sendo possível verificar que dos 161 focos detectados no ano de 1998, 07 ocorreram na faixa oeste de São João do Caru conforme a distribuição espacial gerada na vase de dados (cerca de 4,4\%), 68 ocorreram na porção oeste do Centro Novo do Maranhão (42,2\%), e 86 focos em Bom Jardim (53,4\%). No ano de 2006 esses valores aumentaram bruscamente, houve detecção de 786 focos de calor, destes 02 ocorreram em São João do Caru $(0,3 \%), 453$ no Centro Novo do Maranhão (57,6\%) e 331 em Bom Jardim $(42,1 \%)$. Já em 2016 houve redução de focos de calor, 06 focos de calor em São João do Caru $(1,3 \%), 44$ em Centro Novo do Maranhão $(9,4 \%)$ e 417 em Bom Jardim, representando 89,3\%, município com maior quantidade de focos de calor nesse ano.

O mapa de kernel (Figura 3) representa o resultado da interpolação dos focos de calor, em que foi analisado a intensidade pontual na área em estudo, nos anos de 1998, 2006 e 2016. Observaramse manchas com densidade muito alta (vermelhoescuro) na região norte, sul e leste da REBIO em 1998, nas áreas pertencentes aos municípios de Centro Novo do Maranhão e Bom Jardim, respectivamente. Nos limites do município de Centro Novo do Maranhão, detectou-se a classe muito alta, representada por manchas acentuadas nessa região.

No ano de 2006 a taxa com intensidade muito alta foi observada na região norte, região leste e oeste, com maiores manchas ano norte, nos limites do áreas do município de Centro Novo do Maranhão.

Em pesquisas realizadas por Aragão e Shimabukuro (2010), afirmam-se que o evento de incêndios florestais entre 2001 e 2006 cresceu em $59 \%$ da área, abaixo do normal, e devido a implantação das políticas de anti-deflorestamento. Análise mais detalhada do INPE evidencia-se que em 2007 os incêndios aumentaram em 70\%, de 236.684 para 406.408, e a área queimada quadruplica em relação ao ano anterior, com dados alarmantes de 19.811 para $90.100 \mathrm{~km}^{2}$, mesmo com a redução nesse período do desmatamento (TASKER, ARIMA, 2016).

Em 2016 taxas muito altas, diferentes dos demais anos, foram observadas a leste da reserva próximo ao município de Bom Jardim. As classes de densidade baixa nos anos de 1998 e 2006 aparecem distribuídas ao longo de quase toda área da reserva. 

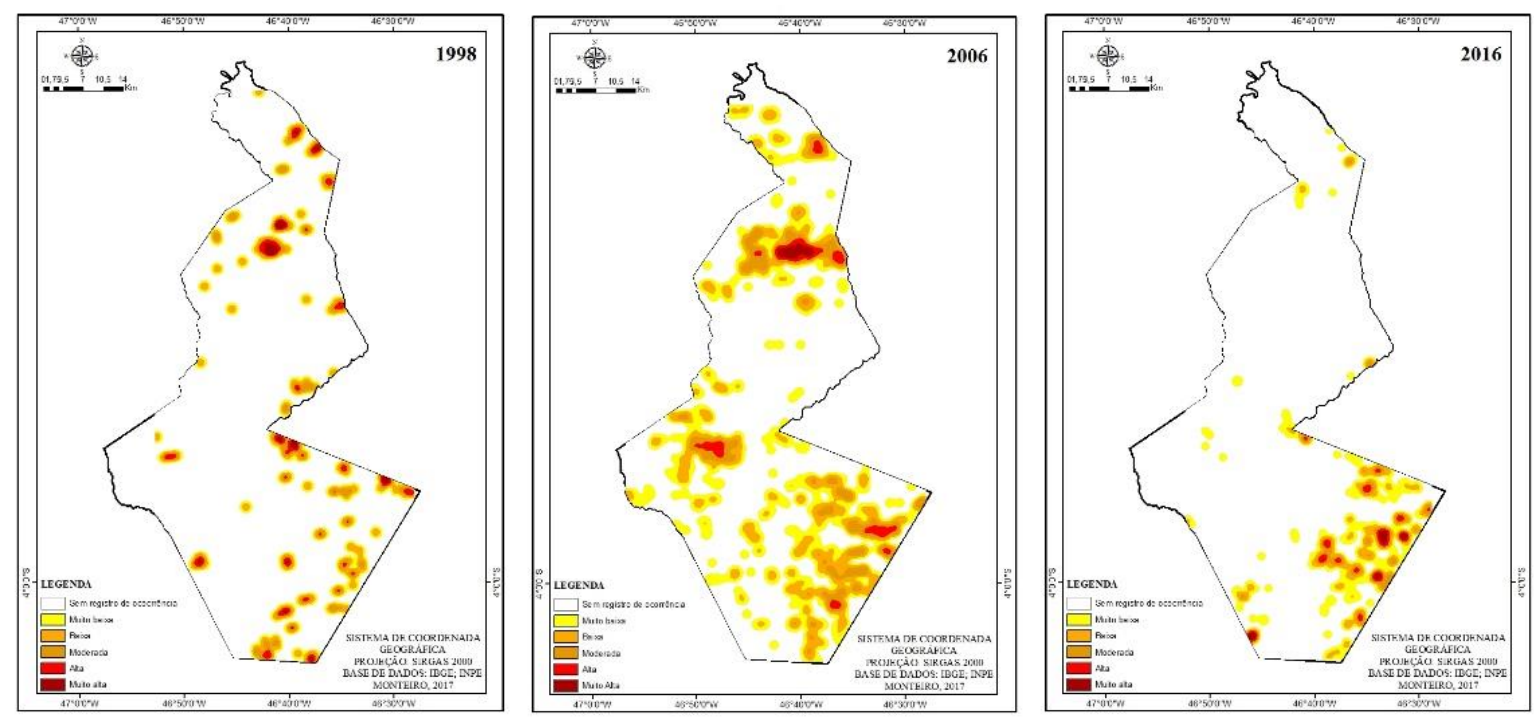

Figura 3 - Mapas de densidade de focos de calor. Fonte: Elaboração própria.

Já em 2016 aparecem a região sul e centro com bem pouco registro ao norte. Foram analisadas ainda áreas sem registro de ocorrência de focos de calor representadas pela cor branca ao longo da área da REBIO do Gurupi.

É possível observar na Figura 4 que representa o quantitativo e sua variação de focos de calor distribuídos pelos meses dos anos de 1998, 2006 e 2016, e uma linha de tendência que mostra o aumento de incidências de focos de calor nos períodos analisados no presente estudo. Segundo o Instituto Nacional de Meteorologia (IMET) no período de janeiro a setembro há quase inexistência de focos devido ao período de maior precipitação, como pode ser observado no quadro abaixo (Figura 5), que apresenta o registro de chuva acumulada mensal do estado do Maranhão, no mesmo período analisado no presente estudo.

De setembro a dezembro com a estação seca e diminuição da chuva, tal hipótese propicia a ampliação das queimadas, já entre os anos de 1998 e 2006 houve aumento sucessivo dos focos com ponto mais alto no mês de dezembro. Entretanto, no ano de 2016 houve redução significativa nos meses de outubro, novembro e dezembro.
Segundo Veldman et al. (2009), Silvério et al. (2013), Brando et al. (2014) as queimadas são constantemente seguidas pela intrusão de espécies de gramíneas, ampliando as cargas de combustíveis e a vivacidade do fogo.

Há uma série de limitações em análises de focos de calor por dados obtidos por sensoriamento remoto, dentre elas, as queimadas de pequena duração, ocorrendo entre as imagens disponíveis, nuvens cobrindo a região na hora do mapeamento e fogo apenas no chão de uma floresta densa, são os mais representativos. Isto pode explicar o fato de em alguns meses não serem registrados dados do satélite para a região estudada. Ou seja, é comum em alguns períodos do ano pouca ou nenhuma ocorrência de focos de calor, que estão relacionas a questões meteorológicas, associadas ao fato de não possuir no sub-bosque extratos florestais (biomassa), que é considerado um dos principais causadores de incêndios florestais (BALCH et al., 2015).

Em estudos realizados por Silva et al. (2018) no sudoeste da Amazônia, destacam que nos anos de 2005 e 2010 houve diminuição de 471.745 hectares de área florestal, ou seja, $90 \%$ da área total foi atingida por incêndios florestais. 


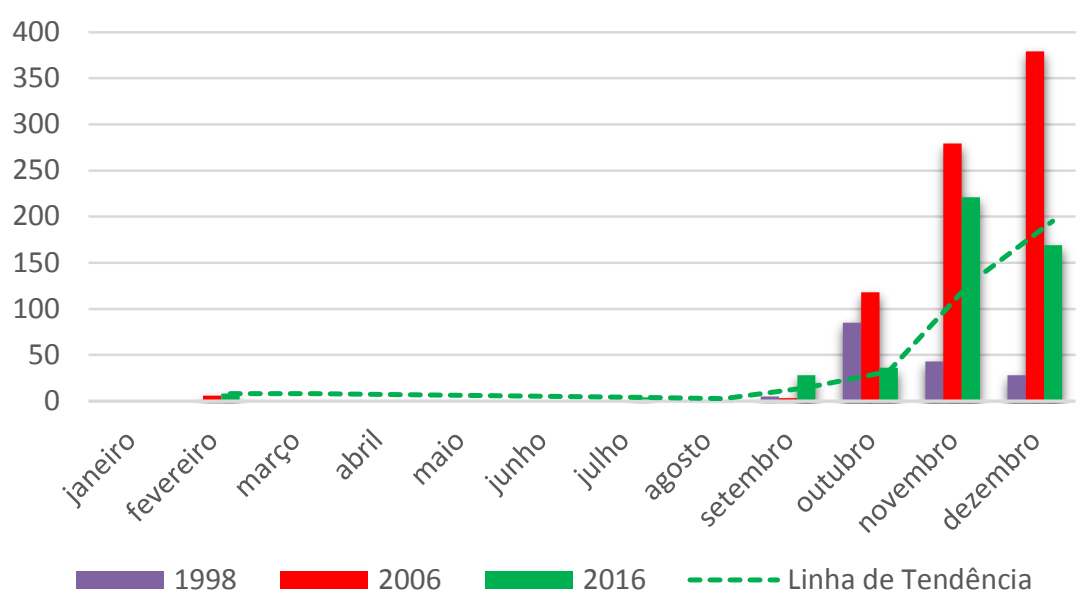

Figura 4 - Comparativo de incidência de focos de calor entre os anos de 1998, 2006 e 2016. Fonte: Elaboração própria.

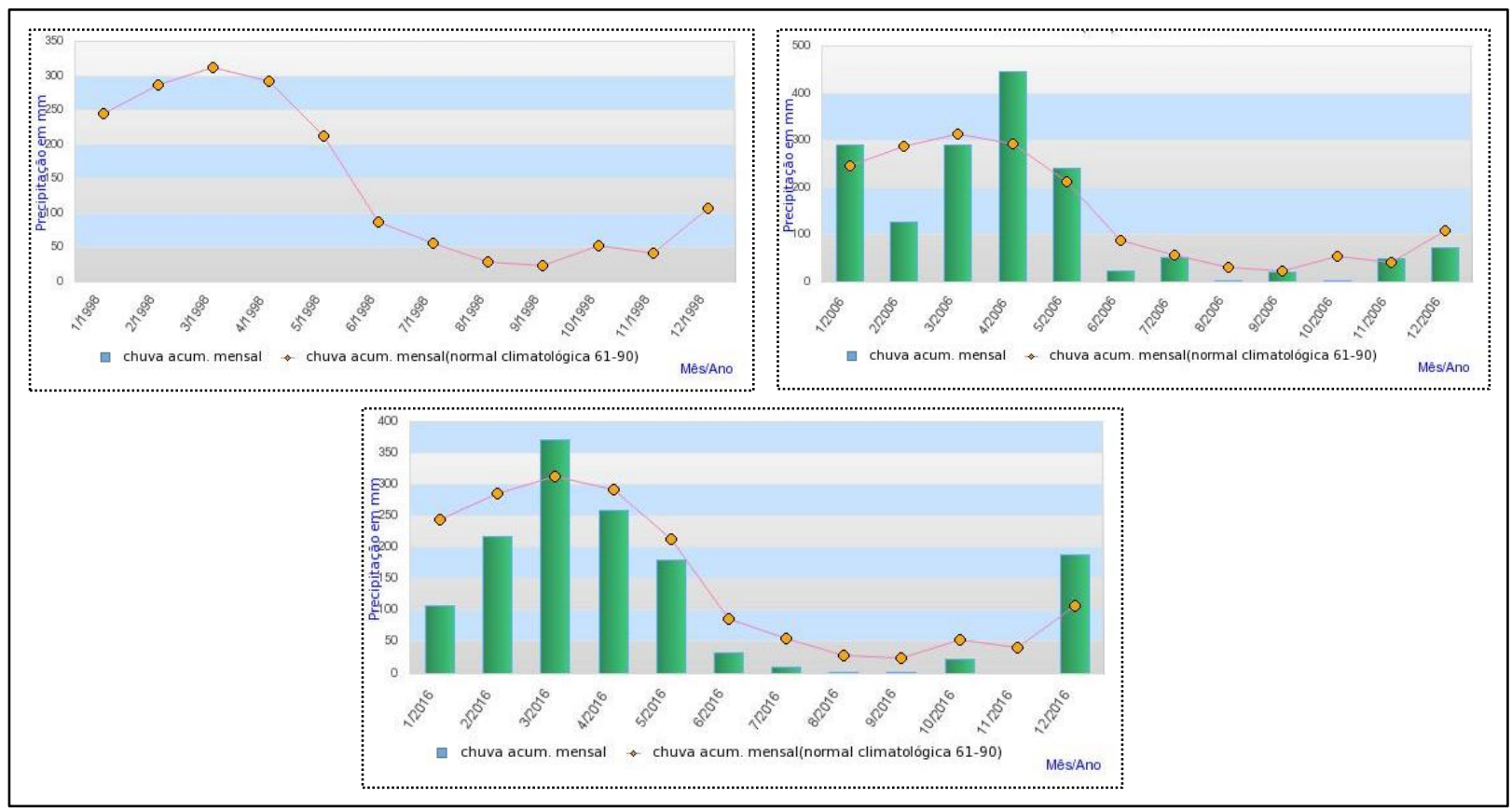

Figura 5 - Chuva acumulada nos anos de 1998, 2006 e2016 no estado do Maranhão. Fonte: IMET (2019).

Os incêndios florestais estão intrinsecamente relacionados à ocupação das fronteiras agrícolas e madeireiras em florestas primárias (TASKER, ARIMA, 2016).

No entanto, apesar da perceptível redução no número de queimadas no ano de 2016, o Maranhão possui fatores que contribuem para o surgimento de focos de incêndios, com as condições naturais do clima, solo e vegetação favoráveis para queimadas, principalmente nos municípios de clima mais seco, permanecendo então em terceiro lugar no ranking elaborado pelo INPE (IMESC, 2016).

\section{CONCLUSÕES}

Diante do exposto, observou-se que os focos de calor se concentram no município de Centro Novo do Maranhão, região leste da REBIO, o qual apresentou o maior número de focos detectados e a mancha chegou ao ápice na classe muito alta no mês de dezembro de 2006, praticamente o dobro em ralação ao ano de 1998.

Já no ano de 2016 houve diminuição dos focos concentrados ao leste do município de Bom Jardim. Verifica-se que maior parte das queimadas e incêndios florestais é detectada nos meses de 
outubro a dezembro, período correspondente de seca e consequente diminuição de chuva. Porém o fogo pode estar relacionado a intervenções humanas, como retirada da cobertura vegetal, tecnologias agrícolas e exploração madeireira na Amazônia.

Todavia, é necessário ser feito uma análise mais criteriosa para identificar um padrão de distribuição mais claro, como, sobreposições com mapas temáticos de uso e ocupação, vegetação ou relevo.

$\mathrm{O}$ uso da geotecnologia é um forte instrumento para análise de impactos ambientais integrado a base de dados do INPE, que nos fornece subsídios de grande importância que visam a prevenção, controle e proteção do meio ambiente, para que estes números sejam cada vez mais reduzidos.

\section{REFERÊNCIAS}

ARAÚJO, E. P.; LOPES, J. R., CARVALHO FILHO, R. Aspectos socioeconômicos e de evolução do desmatamento na Amazônia maranhense. In: Martins, M. B.; Oliveira, T. G. (Org.). Amazônia Maranhense: diversidade e conservação. Belém: MPEG, p.35-44. 2012.

ARAGÃO, L. E. O.C.; SHIMABUKURO, Y. E. The incidence of fire in Amazonian forests with implications for REDD. Science 328 (5983), p. 1275-1278. 2010.

BALCH, J. K.; BRANDO, P. M.; NEPSTAD, D. C.; COE, M. T.; SILVÉRIO, D.; MASSAD, T. J.; DAVIDSON, E. A.; PAUL LEFEBVRE, O.; OLIVEIRASANTOS, C.; ROCHA, W.; CURY, R. T. S.; PARSONS, A.; CARVALHO, K. The Susceptibility of Southeastern Amazon Forests to Fire: Insights from a Large-Scale Burn Experiment. BioScience, sep., v. 65, n. 9. 2015.

BRANDO, P. M.; BALCH, J. K.; NEPSTADE, D. C.; MORTON, D. C.; PUTZ, F. E.; COE, M. T.; SILVÉRIO, D.; MACEDO, M. N.; DAVDSON, E. A.; NÓBREGA, C. C.; ALENCAR, A.; SOARES-FILHO, B. S. Abrupt increases in Amazonian tree mortality due to droughtfire interactions. This article contains supporting information online at www.pnas.org/lookup/suppl/doi:10.1073/pnas.13099111/ -/DCSupplemental. March. 2014.

DRUCK, Suzana. et al.. Análise espacial de dados geográficos. Planaltina, DF: EMBRAPA Cerrados, 2004.

IBAMA, Instituto Brasileiro de Meio Ambiente e Recursos Naturais Renováveis. Plano de Manejo da Reserva Biológica do Gurupi. Brasília, junho de 1999. Disponível em: <http://www.icmbio.gov.br/portal/biodiversidade/unidade s-de-conservacao/biomas brasileiros/amazonia/unidadesde-conservacao amazonia/1998-rebio-do-gurupi.html>. Acesso em 18 out 2017.

INMET - Instituto Nacional de Meteorologia | Eixo Monumental Sul Via S1 - Sudoeste - Brasília-DF. 2019.
INSTITUTO Maranhense de Estudos Socioeconômicos e Cartográficos - IMESC. Relatório de Queimadas Maranhenses. Governo do Maranhão. 2016.

INSTITUTO Chico Mendes de Biodiversidade -ICMBio. Disponível em: http://g1.globo.com/. Acesso em 19 out. 2017.

MOURA, W. C. de; FUKUDA, J. C.; LISBOA, E. A.; GOMES, B. N.; OLIVEIRA, S. L.; SANTOS, M. P.; CARVALHO, A. S.; MARTINS, M. B. A Reserva Biológica do Gurupi como instrumento de conservação da Amazônia Oriental. In: Martins, M B.; Oliveira, T. G. de. Amazônia Maranhense: Diversidade e Conservação. Belém: MPEG, 2011. cap. 01, p. 25-34.

MINISTÉRIO do Meio Ambiente - MMA. Secretaria de Biodiversidade. Cadastro Nacional de Unidades de Conservação. Cadastro Nacional de Unidades de Conservação. Relatório Parametrizado Unidade de Conservação. 2016.

OREN, D. ROMA, J. C. Composição e vulnerabilidade da avifauna da Amazônia maranhense, Brasil. In: Martins, M B.; Oliveira, T. G. de. Amazônia Maranhense: Diversidade e Conservação. Belém: MPEG, 2011. cap. 01, p. 221-249.

PINHEIRO, P. F. V.; SOARES, J. A. C.; NETO, B. S. Desmatamento em Unidades de Conservação de Proteção Integral: $O$ caso da Reserva Biológica do Gurupi - MA. Universidade Federal Rural da Amazônia. XVI Simpósio Brasileiro de Sensoriamento Remoto SBSR. Foz do Iguaçu, Paraná. 2013.

PINHEIRO, P. F. V. Fragmentação florestal em áreas protegidas na Amazônia maranhense e conservação da biodiversidade / Paula Fernanda Viegas Pinheiro. 2019. XVI, 150 f.: il. color. Orientador(a): Prof. ${ }^{a}$ Dra. Maria de Lourdes Pinheiro Ruivo. Coorientação: Prof. ${ }^{a}$ Dra. Maria de Nazaré Martins Maciel Tese (Doutorado) - Programa de Pós-Graduação em Biodiversidade e Biotecnologia, Instituto de Ciências Biológicas, Universidade Federal do Pará, Belém, 2019.

SECRETARIA de Meio Ambiente e Recursos Naturais do Maranhão. Meio Ambiente em foco. Ano I, N 01. Abril 2017. pg 19-20.

SILVA, S. S. Da.; FEARNSIDE, P. M.; GRAÇA, P. M. L. De A.; BROWN, I. F.; ALENCAR, A.; MELO, A. W. F. De. Dynamics of forest fires in the southwestern Amazon. Forest Ecology and Management, v. 424, p. 312-322, set. 2018.

SILVÉRIO, D. V.; BRANDO, P. M.; BALCH, J. K.; PUTZ, F. E.; NEPSTAD, D. C.; OLIVEIRA-SANTOS, C.; BUSTAMANTE, M. M. C. Testing the Amazon savannization hypothesis: fire effects on invasion of a neotropical forest by native cerrado and exotic pasture grasses. Philos Trans R Soc Lond B Biol Sci.; 368 (1619): 20120427, jun. 2013. 
TASKER, K. A.; ARIMA, E. Y. Fire regimes in Amazonia: The relative roles of policy and precipitation. Revista Anthropocene, v. 14, p. 46-57, jun. 2016.

TEIXEIRA, C. V.; CASTRO, C. E. Geoprocessamento no licenciamento ambiental - estudo de caso com mineração. In: Simpósio Brasileiro de Cartografia, 21, 2003, Belo Horizonte. Anais... Rio de Janeiro: SBC, 2003.

UHL, C.; BARRETO, P.; VERÍSSIMO, A.; VIDAL, E.; AMARAL, P.; BARROS, A. C.; SOUZA JUNIOR, C.; JOHNS, J.; GERWING, J. Natural resource management in the Brazilian Amazon. BioScience, 47, 1997. p. 160-168.
VELDMAN, J. W.; MOSTACEDO, B.; PEÑACLAROS, M.; PUTZ, F. E. Selective logging and fire as drivers of alien grass invasion in a Bolivian tropical dry forest. Forest Ecology and Management, v. 258, p. 1643-1649, 15 September. 2009.

VERÍSSIMO, A. A Amazônia brasileira: desenvolvimento e conservação. In: TRIGUEIRO, A. Mundo Sustentável 2: novos rumos para um planeta em crise. São Paulo: Globo, 2012. p. 203-208. 